\title{
Analisis Transportasi Siswa Menuju Sekolah dan Arahan Pengembangannya di Kota Bogor
}

\author{
Analysis of Student Transportaion Towards School and Direction \\ of Development in Bogor City
}

\section{Egi S.M. Purnama ${ }^{1}$, Santun R.P. Sitorus ${ }^{2}$ and Janthy T. Hidayat ${ }^{3}$}

\begin{abstract}
Abstrak: Sekolah merupakan salah satu sistem kegiatan yang membangkitkan pergerakan (generation) dan akan menarik pergerakan (attraction) dari dan menuju permukiman sebagai tempat tinggal siswa. Penelitian ini bertujuan untuk menganalisis tarikan perjalanan siswa SDN dan SMPN di Kota Bogor, menganalisis faktor-faktor yang mempengaruhi pemilihan moda angkutan umum siswa menuju sekolah, menganalisis pemilihan moda angkutan umum siswa menuju sekolah dan menyusun arahan rencana pengembangan transportasi SDN dan SMPN yang lebih efektif di Kota Bogor. Metode yang digunakan yaitu flow mapping, regresi logistik biner, analisis jarak, dan analisis deskriptif. Hasilnya menunjukkan tarikan pergerakan siswa SDN sudah cukup sesuai dengan ketentuan zonasi, sedangkan tarikan pergerakan siswa SMPN menunjukkan hasil yang kurang sesuai dengan ketentuan zonasi. Hasil estimasi faktor yang secara nyata mempengaruhi pemilihan moda angkutan siswa SDN menuju sekolah yaitu jarak sekolah, lama perjalanan, biaya perjalanan, pertimbangan biaya, pertimbangan berjalan kaki, dan pertimbangan waktu. Sementara faktor yang secara nyata/ signifikan mempengaruhi pemilihan moda angkutan siswa SMPN menuju sekolah yaitu jenis kelamin, jarak sekolah, lama perjalanan, dan biaya perjalanan. Pemilihan moda angkutan siswa SDN separuhnya (51\%) menggunakan angkot sebesar sementara selebihnya (49\%) menggunakan moda lainnya. Siswa SMPN sebagian besar (73\%) menggunan angkot untuk berangkat sekolah sementara $27 \%$ siswa lain menggunakan moda angkutan lainnya. Arahan pengembangan transportasi sekolah difokuskan pada penerapan sistem zonasi yang dijalankan secara maksimal agar pergerakan siswa menuju sekolah lebih teratur dan pembagian cluster sekolah agar nantinya pelayanan bus sekolah berjalan secara efektif.
\end{abstract}

Kata Kunci: bangkitan dan tarikan pergerakan, pemilihan moda angkutan, transportasi sekolah

Abstract: School is one system activities that generates movement and will attract movement from settlements as student residence. The objectives of this research are to analyze the attraction of school students, to analyze the factors that influence the selection of public transport modes towards schools, analyzing the selection of student public transport modes and to formulate the direction for effective plan for developing school transportation in Bogor City. The methods used are flow mapping method, binary logistic regression method, proximity analysis, and descriptive analysis. The results show that the attraction of elementary students is sufficiently appropriate because they followed the zoning regulation which can be seen from the majority of students come

\footnotetext{
${ }^{1}$ Program Studi Ilmu Perencanaan Wilayah, Institut Pertanian Bogor

2 Program Studi Ilmu Perencanaan Wilayah, Sekolah Pascasarjana; Departemen Ilmu Tanah dan Sumberdaya Lahan, Institut Pertanian Bogor

${ }^{3}$ Program Studi Perencanaan Wilayah dan Kota, Fakultas Teknik, Universitas Pakuan
} 
from designated zone, while the result of junior high school student's attraction show relatively insufficient because the majority of the students come from outside the designated zones. The estimation results of factors that significantly influence the choice of modes of transportation are gender, school distance, travel time, costs, consideration of costs, consideration of walking, and consideration of time. Half of elementary school students use angkot by $51 \%$ and $49 \%$ others students used other modes towards school. Most junior high school students also use angkot by $73 \%$ and $27 \%$ others students used other modes. The direction of school transportation development is focused on implementing a zoning system that is maximally implemented so that the movement of students to school is more organized and deviding of school clusters so that the school bus service will run effectively.

\section{Keywords: generation and attraction movement, the selection of the mode of transport, school} transport

\section{PENDAHULUAN}

Pertumbuhan jumlah kendaraan bermotor setiap tahun yang terus meningkat menyebabkan sering terjadi kemacetan lalu lintas pada ruas-ruas jalan pada jam-jam sibuk (Rau dan Liputo, 2008). Kurun waktu tahun 2000-2014 pertumbuhan kendaraan mobil penumpang mencapai $415 \%$, mobil bus mencapai $360 \%$, mobil barang $365 \%$ dan sepeda motor mencapai 686\%. Jumlah kendaraan di Kota Bogor berdasarkan Kementerian Perhubungan (2015) mencapai 8.352 unit yang terdiri atas 3.412 unit mobil penumpang umum (MPU), 239 unitbus besar (BB), 73 unit bus sedang (BS) dan 4.529 unit bus kecil (BK) yang menempatkan Kota Bogor di peringkat pertama di wilayah Bodetabek.

Perjalanan secara umum dapat dibedakan menjadi 3 yaitu perjalanan menuju tempat bekerja (trip to work), perjalanan menuju tempat belanja (trip to shop), dan perjalanan menuju tempat belajar (trip to study). Sekolah sebagai sistem kegiatan yang membangkitkan pergerakan (generation) dan akan menarik pergerakan (attraction) dari dan menuju permukiman sebagai tempat tinggal siswa. Salah satu permasalahan sesuai dengan penelitian Brotodewo (2010) menunjukkan kondisi sistem transportasi kawasan metropolitan belum dapat meningkatkan aksesibilitas, meningkatkan efisiensi transportasi, dan produktivitas transportasi untuk pemenuhan indikator keberlanjutan transporasi. Menurut Mansyur et al. (2009) pola pelayanan angkutan umum kota yang mengikuti pola penyebaran aktivitas dan penggunaan lahan kota secara radial menyebabkan beberapa ruas jalan yang dilalui trayek angkutan umum penumpang nonbus akan saling tumpang tindih dan sangat potensial menimbulkan rute gemuk (padat). Keberadaan bangkitan pergerakan pendidikan tersebut menjadi titik-titik yang sangat rawan terjadi penumpukan kendaraan karena banyak angkutan kendaraan (angkot) menunggu penumpang di ruas jalan tersebut. Selain angkutan kota (angkot), siswa juga banyak yang menggunakan kendaraan pengantar-penjemput baik kendaraan pengantar-penjemput pribadi ataupun kendaraan pengantar-penjemput kolektif. Salah satu cara pemerintah untuk menertibkan dan memudahkan siswa menuju sekolah yaitu dengan mengeluarkan Peraturan Menteri Pendidikan Dan Kebudayaan Nomor 14 Tahun 2018 dimana salah satu kriteria prioritas yaitu mempertimbangkan jarak tempat tinggal sekolah sesuai dengan ketentuan zonasi sehingga perlu penelitian untuk mengetahui pergerakan siswa menuju sekolah dan membuat arahan pengembangan transportasi SDN dan sekolah SMPN di Kota Bogor. Penelitian ini dapat menjadi salah satu cara untuk mengembangkan transportasi sekolah yang difokuskan pada pembagian cluster sekolah yang akan berpengaruh terhadap jarak sekolah yang lebih dekat, waktu perjalanan yang lebih singkat dan biaya yang lebih sedikit dengan memperhatikan ketentuan zonasi. Penelitian ini bertujuan untuk: (a) menganalisis tarikan perjalanan siswa SDN dan SMPN di Kota Bogor, (b) menganalisis faktor-faktor yang mempengaruhi pemilihan moda angkutan umum siswa menuju sekolah, (c) menganalisis pemilihan moda angkutan umum siswa menuju sekolah di Kota Bogor dan 
(d) menyusun arahan rencana pengembangan transportasi sekolah dasar negeri dan sekolah menengah pertama negeri yang lebih efektif di Kota Bogor.

\section{METODE}

\section{Lokasi dan Waktu Penelitian}

Penelitian dilaksanakan di 42 sekolah di Kota Bogor, yang terdiri dari kelas I di 22 sekolah dasar negeri dan kelas VII di 20 sekolah menengah pertama negeri. Waktu penelitian dimulai dari tahap penyusunan proposal hingga penyelesaian tesis yaitu Agustus 2017 hingga bulan Maret 2019. Lokasi penelitian disajikan pada Gambar 1.

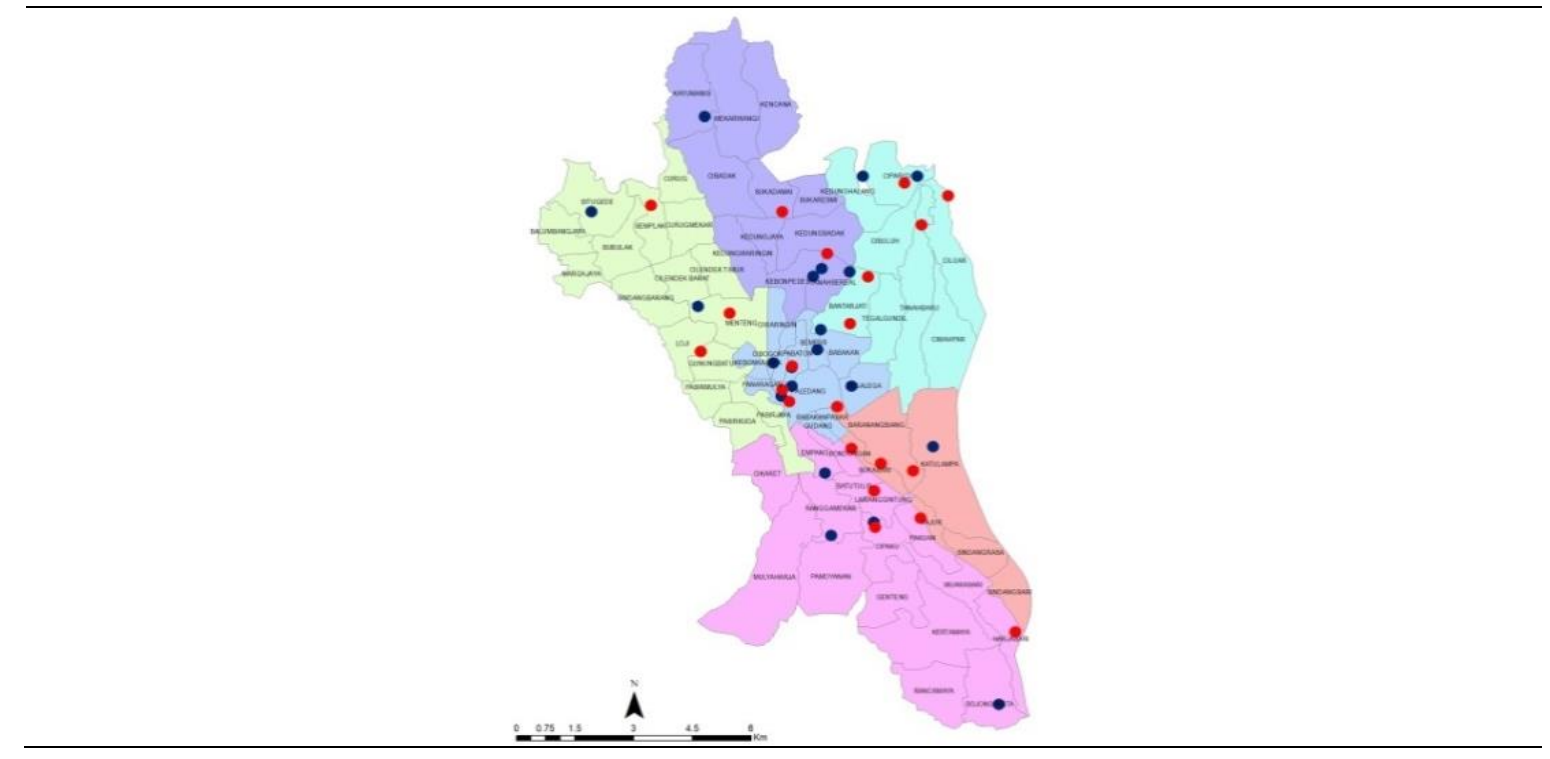

Gambar 1. Peta Lokasi Penelitian

\section{Jenis dan Sumber Data}

Data yang digunakan dalam penelitian ini berupa data primer dan data sekunder. Data primer berupa hasil kuesioner berisi pertanyaan berupa jenjang, jenis kelamin siswa, uang saku siswa, biaya perjalanan, ketersediaan angkutan, jarak berjalan dari tempat berhenti ke sekolah, keamanan angkutan, kenyamanan angkutan, jarak rumah ke sekolah, waktu menuju sekolah dan moda angkutan yang digunakan. Data sekunder terdiri atas data alamat siswa yang bersumber dari situs PPDB Kota Bogor, data lokasi sekolah yang bersumber dari Dinas Pendidikan Kota Bogor, data jumlah dan data trayek angkot yang bersumber dari DLLAJ Kota Bogor, serta dokumen Bogor Transportation Program (B-Top) yang bersumber dari Bappeda Kota Bogor. Alat yang digunakan terdiri dari seperangkat komputer dengan perangkat lunak (software) Ms. Word, Ms. Excel, SPSS v.24, QGIS v.2.18, ArcGIS 10.5.

\section{Analisis Data}

\section{Analisis Bangkitan dan Tarikan Pergerakan (Trip Generation)}

Bangkitan pergerakan merupakan tahapan permodelan transportasi yang memperkirakan jumlah pergerakan yang berasal dari zona asal atau penggunaan lahan dan jumlah pergerakanan yang tertarik ke suatu zona atau penggunaan lahan (Tamin, 1997). Zona permukiman (tempat tinggal) siswa perlu ditentukan terlebih dahulu. Zona ini 
nantinya menjadi bangkitan pergerakan ketika berangkat dan 42 sekolah di Kota Bogor sebagai tarikan pergerakan.

\section{Ketentuan Zonasi}

Ketentuan zonasi yang telah ditetapkan oleh Dinas Pendidikan Kota Bogor memiliki nilai yang berbeda untuk masing-masing jenjang pendidikan. Kelurahan yang beralamat satu kelurahan dengan sekolah yang bersangkutan memiliki nilai yang tinggi (zona 1), kelurahan di luar zona 1 namun masih satu kecamatan memiliki nilai sedang (zona 2), kelurahan di luar zona 1 dan zona 2 namun masih di Kota Bogor memiliki nilai rendah (zona 3), sementara di luar Kota Bogor tidak memiliki nilai. Penilaian zona untuk SMP terdiri atas zona 1 yang memiliki nilai tinggi, zona 2 yang memiliki nilai sedang, zona 3 yang memiliki nilai rendah, zona 4 yang memiliki nilai sangat rendah.

\section{Matriks Asal Tujuan (MAT)}

Matriks pergerakan atau matriks asal tujuan (MAT) adalah matriks berdimensi dua yang berisi informasi besarnya pergerakan antar lokasi (zona) di dalam daerah tertentu. Baris menyatakan zona asal dan kolom menyatakan zona tujuan, sehingga sel matriksnya menyatakan besarnya arus dari zona asal ke zona tujuan. Bentuk pola distribusi dituangkan dalam Matriks Asal Tujuan (MAT) seperti pada Tabel 1.

Tabel 1. Bentuk Umum Matriks Asal Tujuan

\begin{tabular}{|c|c|c|c|c|c|c|}
\hline Asal & 1 & 2 & 3 & $\cdots$ & $\mathbf{n}$ & $\mathbf{O}_{\mathrm{i}}$ \\
\hline 1 & $\mathrm{~T}_{11}$ & $\mathrm{~T}_{12}$ & $\mathrm{~T}_{13}$ & $\ldots$ & $\mathrm{T}_{1 \mathrm{n}}$ & $\mathrm{O}_{1}$ \\
\hline 2 & $\mathrm{~T}_{21}$ & $\mathrm{~T}_{22}$ & $\mathrm{~T}_{23}$ & $\ldots$ & $\mathrm{T}_{1 \mathrm{n}}$ & $\mathrm{O}_{2}$ \\
\hline m & $\begin{array}{l}\ldots \\
\mathrm{T}_{\mathrm{m} 1}\end{array}$ & $\begin{array}{l}\ldots \\
\mathrm{T}_{\mathrm{m} 2}\end{array}$ & $\begin{array}{l}\ldots \\
\mathrm{T}_{11}\end{array}$ & $\begin{array}{l}\ldots \\
\ldots\end{array}$ & $\begin{array}{l}\ldots \\
\mathrm{T}_{\mathrm{m}}\end{array}$ & $\begin{array}{l}\ldots \\
\mathrm{O}_{m}\end{array}$ \\
\hline$D_{j}$ & $D_{j 1}$ & $\mathrm{D}_{\mathrm{j} 2}$ & $D_{\mathrm{j} 3}$ & & $D_{j n}$ & \\
\hline
\end{tabular}

Sumber: Tamin 1997

dimana;

$T i j=$ pergerakan dari zona asal $i$ (kelurahan) ke zona tujuan $j$ (42 sekolah di Kota Bogor)

$O i=$ jumlah pergerakan yang berasal dari zona asal $i$ (kelurahan)

$D j=$ jumlah pergerakan yang menuju zona $j$ (42 sekolah di Kota Bogor)

\section{Analisis Pola Distribusi Perjalanan}

Metode analisis untuk mengetahui pola distribusi perjalanan siswa dari zona pemukiman (tempat tinggal) menuju sekolah di Kota Bogor yaitu dengan menggunakan metode FlowMapping pada program QGIS v.2.18.27 dan metode Proximity pada program ArcGIS 10.5.

\section{FlowMapping}

Pola distribusi perjalanan siswa sekolah dilakukan dengan cara penentuan zona permukiman siswa. Penentuan zona menjadi dasar untuk selanjutnya menentukan cetroid, centroid connector, node and link serta pembuatan database. Data tersebut menjadi input dalam melakukan iterasi pada program FlowMapper. Salah satu keluaran dari program FlowMapper ini yaitu dapat mengetahui garis keinginan (desire line) perjalanan siswa menuju sekolah masing-masing yang berada di Kota Bogor. Setiap ketebalan garis menggambarkan seberapa banyak garis keinginan perjalanan siswa. Garis keinginan juga dapat menggambarkan bagaimana pola pergerakan perjalanannya. 


\section{Analisis Proximity}

Analisis ini digunakan untuk mengetahui cakupan pelayanan setiap sekolah yang berada di Kota Bogor sesuai dengan ketentuan yang berlaku seperti yang tercantum dalam SNI 03-1733-2004 tentang Tata cara perencanaan lingkungan perumahan di perkotaan. Cakupan pelayanan untuk SD dan SMP yaitu $1 \mathrm{Km}$ dari lokasi. Analisis ini juga digunakan untuk pengelompokkan (clustering) sekolah.

\section{Analisis Regresi Logistik Biner}

Regresi logistik merupakan salah satu metode stasitika yang digunakan untuk menjelaskan hubungan antara peubah respon yang memiliki dua kategori atau lebih dengan satu atau lebih peubah penjelas yang memiliki skala kategorik atau kontinu (Hosmer dan Lemeshow, 2000). Metode analisis regresi untuk memprediksi variabel yang berpengaruh terhadap bangkitan dan tarikan perjalanan siswa sekolah dasar negeri dan sekolah menengah pertama negeri di Kota Bogor menggunakan analisis regresi logistik dimana hasil pengamatan memiliki $\mathrm{p}$ peubah bebas yang ditunjukkan oleh vektor $\mathrm{X}^{\prime}=\left(\mathrm{x}_{1}\right.$, $\mathrm{x}_{2}, \mathrm{x}_{3}, \ldots \mathrm{x}_{\mathrm{p}}$ ) dengan peubah respons $\mathrm{Y}$, dimana $\mathrm{Y}$ mempunyai dua kemungkinan nilai yaitu 0 dan $1, Y=1$ menyatakan bahwa respons memiliki kriteria yang ditentukan (present) dan sebaliknya $\mathrm{Y}=0$ tidak memiliki kriteria (absent). Peubah respons $\mathrm{Y}$ mengikuti sebaran Bernoulli dengan parameter $\pi(\mathrm{x})$ dan fungsi sebaran peluang :

$$
f\left(Y=y^{\prime}\right)=\pi\left(x_{i}\right)^{y_{i}}\left[1-\pi\left(x_{i}\right)\right]^{1-y_{i}}
$$

Model umum persamaan peluang regresi logistik dengan peubah penjelas adalah:

$$
E\langle Y \mid x\rangle=\pi(x)=\frac{e^{g(x)}}{1+e^{g(x)}}
$$

dimana komponen $g(x)=\ln \left[\frac{\pi(x)}{1-\pi(x)}\right]=\beta_{0}+\beta_{1} x_{1}+\beta_{2} x_{2}+\cdots+\beta_{p} x_{p}$ merupakan penduga logit sebagai fungsi linear dari peubah penjelas.

\section{Pemilihan Variabel}

Variabel terikat (dependent) yaitu jenis moda angkutan siswa, sementara variabel bebas (independent) adalah jenis kelamin siswa $\left(\mathrm{X}_{1}\right)$, uang saku $\left(\mathrm{X}_{2}\right)$, jarak dari rumah ke sekolah $\left(\mathrm{X}_{3}\right)$, lama perjalanan dari rumah ke sekolah $\left(\mathrm{X}_{4}\right)$, biaya perjalanan dalam sehari $\left(\mathrm{X}_{5}\right)$, ketersediaan angkutan $\left(\mathrm{X}_{6}\right)$, biaya perjalanan $\left(\mathrm{X}_{7}\right)$, kenyamanan angkutan $\left(\mathrm{X}_{8}\right)$, jarak berjalan ke tempat henti $\left(\mathrm{X}_{9}\right)$, keamanan angkutan $\left(\mathrm{X}_{10}\right)$, waktu perjalanan $\left(\mathrm{X}_{11}\right)$.

\section{Pengujian Parameter}

Pengujian parameter model dilakukan untuk mengetahui signifikansi suatu peubah penjelas yang terdapat dalam model. Uji yang digunakan adalah uji $G$, yaitu uji rasio kemungkinan maksimum (likelihood ratio test). Uji G juga dilakukan utuk mengetahui nilai signifikansi peubah penjelas secara serentak atau keseluruhan. Adapun persamaan umum uji G adalah:

dimana:

$$
G=-\ln \left[\frac{L_{0}}{L_{1}}\right]
$$

$\mathrm{L}_{0} \quad$ : nilai kemungkinan tanpa peubah

$\mathrm{L}_{1} \quad$ : nilai kemungkinan dengan peubah

Pengambilan keputusan hipotesis nol ditolak apabila nilai $G>X_{p(a)}^{2}$ atau nilai $\mathrm{p}<\alpha$. Selain uji G, uji Wald dilakukan untuk menguji secara parsial masing-masing koefisien peubah (bebas). Menurut Maharani (2007) uji Wald didefinisikan sebagai berikut:

$$
W=\frac{\hat{\beta}}{S E\left(\hat{\beta}_{i}\right)}
$$


Nilai $\hat{\beta}$ merupakan dugaan koefisien dari peubah penjelas, sedangkan $\hat{S E}\left(\hat{\beta}_{j}\right)$ merupakan simpangan baku dari pendugaan parameternya. Statistik uji-Wald mengikuti sebaran normal baku (Chi Square). Hipotesis nol ditolak jika $|\mathrm{W}|>\mathrm{Z}_{\alpha / 2}$.

\section{Ketepatan Klasifikasi Model (Goodness of Fit)}

Tujuan akhir dari model regresi logistik yaitu untuk mengetahui probabilitas suatu peluang yang tergantung dari nilai kovariat x. Menurut Liu (2007), Goodness of Fit dirancang untuk menentukan kesesuaian suatu model regresi logistik yang digunakan. Suatu model dapat dikatakan baik (tepat) apabila model tersebut memiliki peluang salah klasifikasi yang minimal (Hosmer dan Lemeshow, 2000). Hosmer et al. (1997) juga menyebutkan bahwa memeriksa ketepatan suatu model (goodness of fit) yaitu dengan melihat variasi residu yang kecil, tidak ada kecenderungan yang sistematis, serta mengikuti variabilitas model. Ketepatan prediksi diketahui dari cutpoint (c) yang ditentukan untuk memperoleh kesesuaian dugaan terhadap amatan dan dibandingkan dengan peluang dugaan $\pi(\mathrm{x})$. Jika $\pi(\mathrm{x})>\mathrm{c}$ maka tolak $\mathrm{H}_{0}$, sementara jika Jika $\pi(\mathrm{x})<\mathrm{c}$ maka terima $\mathrm{H}_{0}$.

\section{Analisis Statistik Deskriptif}

Penyajian data yang diperoleh diolah dalam bentuk tabel dan selanjutnya dapat disajikan dalam bentuk histogram maupun tabel batang. Histogram atau tabel batang dapat menjelaskan karakteristik responden, karakteristik pergerakan dan moda angkutan yang digunakan siswa sekolah yang berada di Kota Bogor. Histogram atau tabel batang juga dapat menjelaskan persentase proporsi karakteristik-karakteristik tersebut terhadap pemilihan moda siswa sekolah yang berada di Kota Bogor. Secara teori tidak ada ketentuan pengambilan range pada tiap kelompok histogram. Range tersebut diambil secara subjektif oleh peneliti sendiri sebelum survei dilaksanakan. Sebagai contoh, pengolahan data dapat dipisah menjadi jenjang sekolah, Sekolah Dasar (SD), dan Sekolah Menengah Pertama (SMP).

\section{Arahan Rencana Pengembangan Transportasi Sekolah di Kota Bogor}

Analisis yang digunakan untuk menyusun arahan rencana pengembangan transportasi sekolah dasar negeri dan sekolah menengah negeri di Kota Bogor adalah metode analisis deskriptif. Analisis ini merupakan analisis yang digunakan untuk menjelaskan, menguraikan, menggambarkan, menganalisis, mensitesis, dan menjabarkan hasil analisis sebelumnya sehingga dapat diperoleh pemahaman yang lebih obyektif dan realistis terhadap keadaan sesungguhnya. Bangkitan (pemukiman) dan tarikan (sekolah) dikelompokkan agar memudahkan untuk penyusunan arahan rencana pengembangan transportasi sekolah dapat lebih efektif. Pengelompokkan sekolah didasarkan pada kedekatan jarak sekolah di suatu kawasan dengan mempertimbangkan sistem transportasi sekitar kawasan tersebut, sementara pengelompokkan permukiman didasarkan pada kedekatan setiap satuan permukiman.

\section{HASIL DAN PEMBAHASAN}

\section{Tarikan Perjalanan Siswa SDN dan SMPN di Kota Bogor}

Tarikan perjalanan siswa sekolah dasar negeri dan sekolah menengah pertama negeri di Kota Bogor dilakukan untuk mengetahui besaran nilai tarikan masing-masing sekolah. Tarikan perjalanan didasarkan pada alamat masing-masing siswa yang kemudian disandingkan dengan ketentuan zonasi. Hasil analisis tarikan perjalanan siswa SDN menunjukkan bahwa secara umum tarikan perjalanan sudah cukup sesuai karena sudah 
cukup mengikuti ketentuan zonasi yang dapat dilihat dari mayoritas siswa berasal dari zona yang ditetapkan (Gambar 2). Hanya SDN Semplak 2, SDN Polisi 4, SDN Cibuluh 1, dan SDN Gununggede yang mayoritas siswanya berasal dari luar zona yang ditentukan. Siswa di SDN Cibuluh 1 dan SDN Gununggede mayoritas berasal dari luar zona namun masih dari dalam Kota Bogor. SDN Semplak 2 dan SDN Polisi 4 memiliki tarikan yang tinggi dari luar Kota Bogor berarti mayoritas siswa di sekolah tersebut berasal dari luar Kota Bogor. Sebanyak 35\% siswa SDN Semplak 2 berasal dari Kec. Kemang, Kab. Bogor dan 19\% siswa SDN Polisi 4 berasal dari Kecamatan Ciomas, Kab. Bogor. Sebanyak 15 SDN dari 22 SDN yang diteliti memiliki jumlah siswa dari luar Kota Bogor $>10 \%$, padahal dalam Permendikbud No. 14 tahun 2018 mensyaratkan maksimal siswa yang berasal dari luar daerah sebanyak $10 \%$.

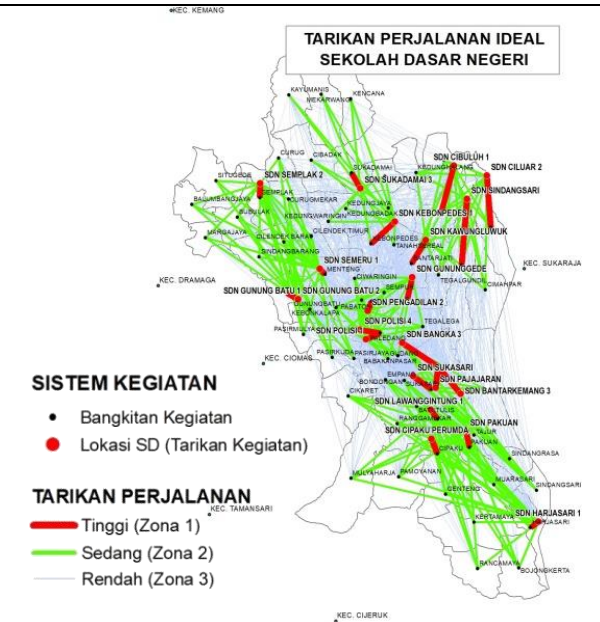

(a)

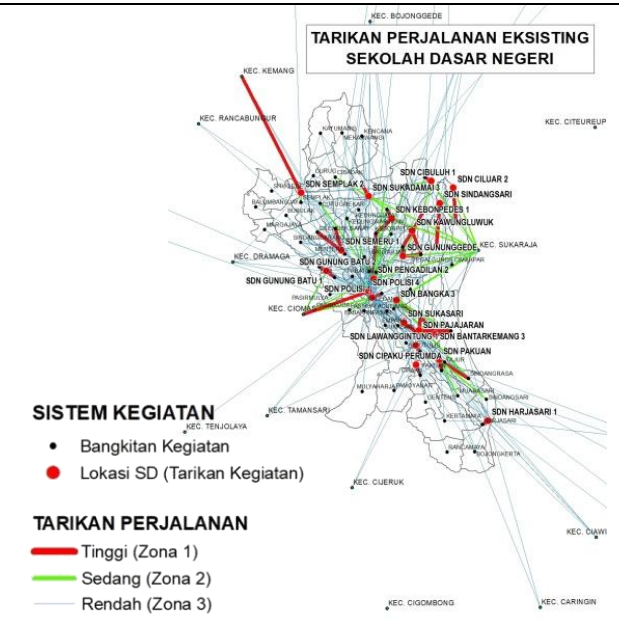

(b)

Gambar 2. (a) Tarikan perjalanan ideal dan (b) tarikan perjaanan eksisting SDN

Hasil analisis tarikan perjalanan siswa SMPN menunjukkan secara umum ketentuan zonasi relatif belum cukup baik diterapkan karena mayoritas siswa berasal dari luar zona yang ditetapkan (Gambar 3). Tarikan pergerakan di SMPN 1, SMPN 2, SMPN 10 dan SMPN 11 Kota Bogor memiliki sedikit siswa yang berasal dari zona 1 yang seharusnya menjadi mayoritas di sekolah tersebut. Mayoritas siswa SMPN 1 Kota Bogor berasal dari zona 3 (Kel. Katulampa 10\%), mayoritas siswa SMPN 2 Kota Bogor berasal dari zona 2 (Kel. Kedungwaringin 15\%) dan luar kota (Kec. Sukaraja, Kab. Bogor 13\%), mayoritas siswa SMPN 10 Kota Bogor berasal dari zona 2 (Kel. Cikaret 12\%, Kel. Batutulis 11\%), dan mayoritas siswa SMPN 11 Kota Bogor dari luar kota (Kec. Sukaraja, Kab. Bogor 18\%). SMPN 4 Kota Bogor dan SMPN 19 juga memiliki siswa yang mayoritas dari luar Kota Bogor yaitu dari Kec. Kemang dan Kec. Sukaraja. Sebanyak 15 SMPN dari 22 SMPN yang diteliti memiliki jumlah siswa dari luar Kota Bogor $>10 \%$ yang berarti bahwa sekolah tersebut memiliki jumlah siswa yang berasal dari luar kota melebihi kuota maksimal yang ditentukan.

\section{Faktor-faktor yang Mempengaruhi Pemilihan Moda Angkutan Siswa Menuju Sekolah}

Analisis faktor-faktor pemilihan moda angkutan dibagi menjadi dua berdasarkan jenjang sekolah yaitu, sekolah dasar negeri (SDN) dan sekolah menengah pertama negeri (SMPN). Pembagian dilakukan karena adanya perbedaan karakteristik responden antara responden siswa kelas I (SD) dengan siswa kelas VII (SMP). Metode yang digunakan dalam analisis ini adalah regresi logistik biner. 


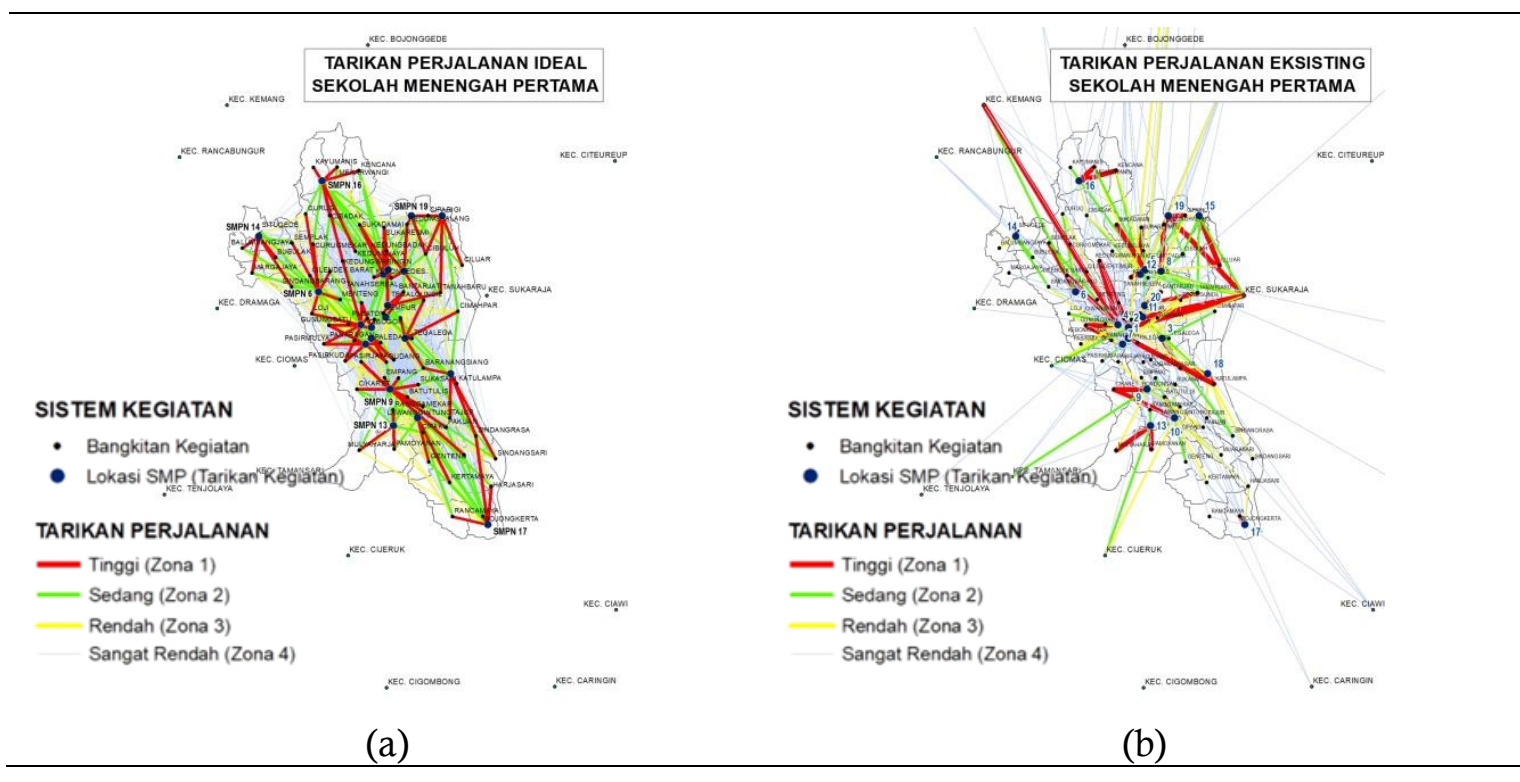

Gambar 3. (a) Tarikan perjalanan ideal dan (b) tarikan perjalanan eksisting SMPN

Hasil analisis untuk jenjang SDN menghasilkan 7 dari 11 variabel independen lolos uji bivariat dan lolos uji multivariat yaitu uang saku $\left(\mathrm{X}_{2}\right)$, jarak sekolah $\left(\mathrm{X}_{3}\right)$, lama perjalanan $\left(\mathrm{X}_{4}\right)$, biaya perjalanan $\left(\mathrm{X}_{5}\right)$, pertimbangan biaya $\left(\mathrm{X}_{7}\right)$, pertimbangan berjalan kaki $\left(\mathrm{X}_{9}\right)$, dan pertimbangan waktu $\left(\mathrm{X}_{11}\right)$. Hasil Omnibus Test dari 7 variabel independen tersebut diperoleh nilai Chi-Square hitung sebesar 243,709 > Chi-Square tabel sebesar 16,013 menunjukkan bahwa variabel independen sesuai untuk dimasukkan ke dalam model, sedangkan nilai Chi Square Hosmer and Lemeshow Test hitung sebesar 14,071 < Chi Square tabel sebesar 14,449 menunjukkan bahwa model dapat diterima dan pengujian hipotesis dapat dilakukan sebab tidak ada perbedaan signifikan antara model dengan nilai observasinya. Berdasarkan Tabel 2 nampak bahwa hampir semua variabel independen nilai $P$ value uji wald (Sig) $<0,05$ kecuali faktor uang saku, artinya j jarak sekolah $\left(\mathrm{X}_{3}\right)$, lama perjalanan $\left(\mathrm{X}_{4}\right)$, biaya perjalanan $\left(\mathrm{X}_{5}\right)$, pertimbangan biaya $\left(\mathrm{X}_{7}\right)$, pertimbangan berjalan kaki $\left(\mathrm{X}_{9}\right)$, dan pertimbangan waktu $\left(\mathrm{X}_{11}\right)$ mempunyai pengaruh parsial yang signifikan terhadap pemilihan moda di dalam model.

Tabel 2. Pendugaan Parameter SDN

\begin{tabular}{|c|c|c|c|c|c|c|}
\hline \multirow{2}{*}{ Variabel } & \multirow{2}{*}{ B } & \multirow{2}{*}{ Wald } & \multirow{2}{*}{ Sig. } & \multirow{2}{*}{$\operatorname{Exp}(B)$} & \multicolumn{2}{|c|}{ 95\% C.I.for EXP(B) } \\
\hline & & & & & Lower & Upper \\
\hline Uang saku (м) & $-0,457$ & 0,668 & 0,414 & 0,633 & 0,212 & 1,894 \\
\hline Jarak sekolah (D) & 1,154 & 8,405 & $0,004^{*}$ & 3,172 & 1,453 & 6,922 \\
\hline Lama perjalanan $(\mathrm{T})$ & $-2,964$ & 12,420 & $0,000^{*}$ & 0,052 & 0,010 & 0,268 \\
\hline Biaya perjalanan (c) & 4,665 & 30,611 & $0,000^{*}$ & 106,122 & 20,331 & 553,927 \\
\hline Pertimbangan biaya (RC) & 1,190 & 10,693 & $0,001^{*}$ & 3,289 & 1,611 & 6,713 \\
\hline $\mathrm{X}_{9} \quad$ Pertimb jalan kaki (Rw) & $-2,096$ & 29,360 & $0,000^{*}$ & 0,123 & 0,058 & 0,262 \\
\hline $\mathrm{X}_{11}$ Pertimbangan waktu (RT) & $-2,162$ & 25,145 & $0,000^{*}$ & 0,115 & 0,049 & 0,268 \\
\hline Konstanta & 0,376 & 0,213 & 0,213 & 1,457 & & \\
\hline
\end{tabular}

*variabel yang signifikan memberi pengaruh

Hasil Pseudo R-Square sebesar 0,666 menunjukkan bahwa kemampuan variabel independen dalam menjelaskan variabel dependen adalah sebesar 0,666 atau $66,6 \%$ dan 33,4\% faktor lain di luar model yang menjelaskan variabel dependen. Adapun persamaan akhir yang dibentuk untuk jenjang SDN adalah sebagai berikut: 


$$
\operatorname{Ln} \frac{P}{1-P}=0,376+1,154_{D}-2,964_{T}+4,665_{C}+1,190_{R C}-2,162_{R W}-2,162_{R T}
$$

Hasil analisis untuk jenjang SMPN menghasilkan 7 dari 11 variabel independen lolos uji bivariat dan lolos uji multivariat yaitu jenis kelamin $\left(X_{1}\right)$, uang saku $\left(X_{2}\right)$, jarak sekolah $\left(\mathrm{X}_{3}\right)$, lama perjalanan $\left(\mathrm{X}_{4}\right)$, biaya perjalanan $\left(\mathrm{X}_{5}\right)$, pertimbangan berjalan kaki $\left(\mathrm{X}_{9}\right)$, dan pertimbangan waktu $\left(\mathrm{X}_{11}\right)$. Hasil Omnibus Test dari 7 variabel independen tersebut diperoleh nilai Chi-Square hitung sebesar 253,947 > Chi-Square tabel sebesar 16,013 menunjukkan bahwa variabel independen sesuai untuk dimasukkan ke dalam model, sedangkan nilai $C h i$ Square Hosmer and Lemeshow Test hitung sebesar 3,587 < Chi Square tabel sebesar 14,449 sehingga menerima $\mathrm{H}_{0}$, yang menunjukkan bahwa model dapat diterima dan pengujian hipotesis dapat dilakukan sebab tidak ada perbedaan signifikan antara model dengan nilai observasinya. Berdasarkan Tabel 3 nampak bahwa variabel independen yang memiliki nilai $P$ value uji wald (Sig) $<0,05$ adalah jenis kelamin $\left(\mathrm{X}_{1}\right)$, jarak sekolah $\left(\mathrm{X}_{3}\right)$, lama perjalanan $\left(\mathrm{X}_{4}\right)$, dan perjalanan $\left(\mathrm{X}_{5}\right)$ mempunyai pengaruh parsial yang signifikan terhadap pemilihan moda di dalam model.

Tabel 3. Pendugaan Parameter SMPN

\begin{tabular}{|c|c|c|c|c|c|c|}
\hline \multirow{2}{*}{ Variabel } & \multirow{2}{*}{ B } & \multirow{2}{*}{ Wald } & \multirow{2}{*}{ Sig. } & \multirow{2}{*}{$\operatorname{Exp}(B)$} & \multicolumn{2}{|c|}{ 95\% C.I.for EXP(B) } \\
\hline & & & & & Lower & Upper \\
\hline Jenis kelamin (s) & 5,314 & 24,158 & $0,000^{*}$ & 203,237 & 24,414 & 1691,840 \\
\hline Uang saku (м) & 0,143 & 0,028 & 0,867 & 1,154 & 0,216 & 6,160 \\
\hline $\mathrm{X}_{3}$ Jarak sekolah (D) & $-2,185$ & 5,862 & $0,015^{*}$ & 0,112 & 0,019 & 0,660 \\
\hline Lama perjalanan ( & 3,787 & 44,814 & $0,000^{*}$ & 44,111 & 14,557 & 133,671 \\
\hline Biaya perjalanan (c) & 2,837 & 26,335 & $0,000^{*}$ & 17,063 & 5,774 & 50,421 \\
\hline $\mathrm{X}_{9} \quad$ Pertimb jalan kaki (RW) & $-0,328$ & 0,467 & 0,495 & 0,720 & 0,281 & 1,847 \\
\hline $\mathrm{X}_{11}$ Pertimbangan waktu (RT) & $-0,124$ & 0,080 & 0,777 & 0,883 & 0,374 & 2,085 \\
\hline Konstanta & $-4,575$ & 12,449 & 0,000 & 0,010 & & \\
\hline
\end{tabular}

*variabel yang signifikan memberi pengaruh

Hasil Pseudo R-Square sebesar 0,735 menunjukkan bahwa kemampuan variabel independen dalam menjelaskan variabel dependen adalah sebesar 0,735 atau $73,5 \%$ dan $26,5 \%$ faktor lain di luar model yang menjelaskan variabel dependen. Adapun persamaan akhir yang dibentuk untuk jenjang SMPN adalah sebagai berikut:

$$
\operatorname{Ln} \frac{P}{1-P}=-4,575+5,314_{S}-2,185_{D}+3,787_{T}+2,837_{C}
$$

\section{Pemilihan Moda Angkutan Siswa Menuju Sekolah}

Analisis pemilihan moda angkutan siswa dibagi berdasarkan jenjang sekolah yaitu SDN dan SMPN. Data yang digunakan bersumber dari hasil wawancara dan kuesioner. Moda angkutan dibedakan atas 4 moda yaitu moda angkutan perkotaan (angkot), angkutan antar jemput baik antar jemput pribadi maupun kolektif, kendaraan umum berbasis online dan siswa yang berjalan kaki menuju sekolah masing-masing.

Hasil analisis untuk jenjang SDN menunjukkan bahwa lebih dari separuh (51\%) siswa di 22 sekolah dasar negeri di Kota Bogor menggunakan angkot menuju sekolah maupun pulang sekolah. Siswa lainnya berjalan kaki 20\%, menggunakan kendaraan umum berbasis online 19\% dan menggunakan angkutan antar jemput 10\%. Siswa yang paling banyak menggunakan angkot yaitu siswa yang bersekolah di SDN Bangka 3, SDN Polisi 4 dan SDN Sukadamai. Siswa di SDN Harjasari 1 lebih banyak berjalan kaki menuju sekolah. Hal tersebut dikarenakan siswa di SDN Harjasari 1 lebih banyak bertempat tinggal di sekitar sekolah sehingga untuk menuju atau pulang sekolah masih memungkinkan untuk berjalan kaki. 


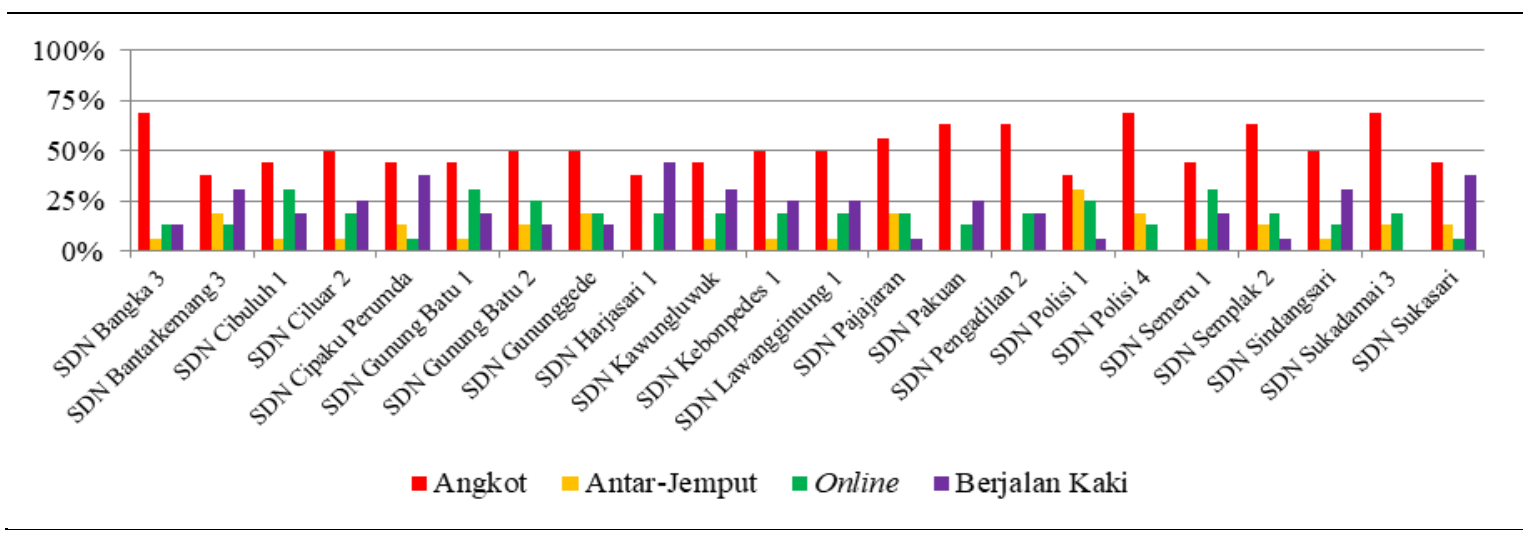

Gambar 5. Persentase pemilihan moda angkutan siswa SDN di Kota Bogor

Secara umum 73\% siswa di 20 sekolah menengah pertama negeri di Kota Bogor menggunakan angkot menuju sekolah maupun pulang sekolah. Siswa lainnya menggunakan kendaraan umum berbasis online, berjalan kaki, atau menggunakan angkutan antar jemput dengan nilai berturut-turut $17 \%, 6 \%$ dan $4 \%$. Siswa yang paling banyak menggunakan angkot yaitu siswa yang bersekolah di SMP Negeri 7 Kota Bogor, diikuti oleh SMP Negeri Kota Bogor, sementara yang paling sedikit menggunakan angkot yaitu siswa di SMP Negeri 18 Kota Bogor.

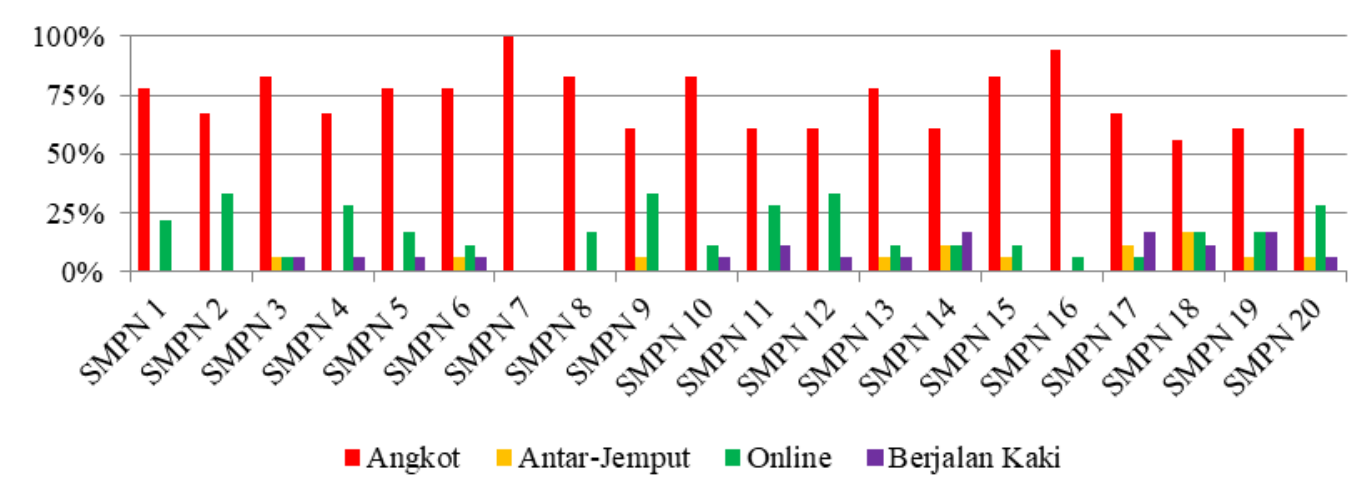

Gambar 5. Persentase pemilihan moda angkutan siswa SMPN di Kota Bogor

\section{Arahan Rencana Pengembangan Transporasi Sekolah}

Sesuai dengan hasil analisis pertama, tarikan pergerakan siswa baik siswa SDN maupun siswa SMPN di Kota Bogor masih belum sepenuhnya sesuai dengan ketentuan zonasi terutama tarikan pergerakan siswa SMPN. Perlu penerapan peraturan yang konsisten agar bangkitan (asal) pergerakan siswa sesuai zonasinya sehingga tarikannya lebih teratur. Penerapan ketentuan zonasi akan mengurangi jarak tempuh dan waktu siswa menuju sekolah karena sistem zonasi tersebut dirancang untuk mendekatkan jarak siswa menuju sekolah. Sekolah yang ada selanjutnya dapat dibagi menjadi 30 kelompok/ cluster (Gambar 6). Pembagian cluster ini untuk mengefektifkan perjalanan, baik waktu perjalanan, jarak perjalanan, keamanan dan kenyamanan bagi siswa. Pemerintah Kota Bogor dan pihak sekolah perlu mengupayakan untuk mengadakan bus sekolah yang dapat dikelola oleh pemerintah, pihak sekolah atau pihak swasta agar siswa SDN dan SMPN yang selama ini sebagian besar menggunakan angkutan umum selanjutnya diarahkan untuk menggunakan bus sekolah. Penggunaan bus sekolah juga dapat mengurangi penumpukan 
angkutan umum di ruas jalan yang berada di dekat sekolah. Operasional bus sekolah didasarkan pada cluster sehingga bus sekolah dalam satu kali perjalanan dapat langsung mengantarkan ke beberapa sekolah.

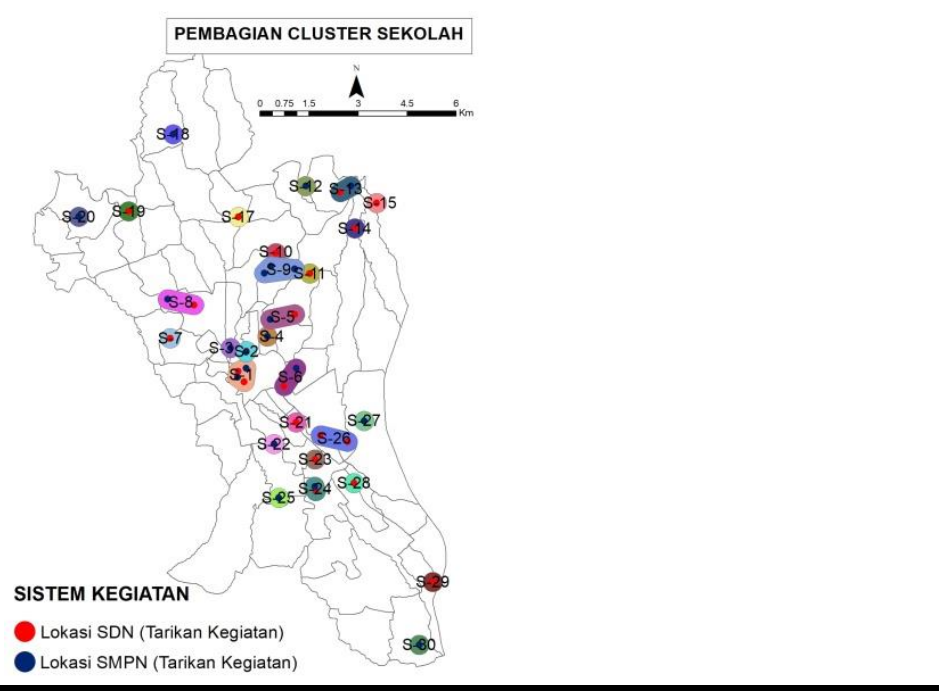

Gambar 6. Pembagian cluster sekolah

\section{KESIMPULAN}

Tarikan pergerakan siswa SDN sebagian besar sudah sesuai dengan sistem zonasi yang ditetapkan oleh pemerintah dan tarikan pergerakan siswa SMPN di Kota Bogor relatif belum sesuai dengan ketentuan zonasi yang ditetapkan oleh pemerintah. Sejumlah 15 SDN dan 15 SMPN di Kota Bogor memiliki jumlah siswa yang berasal dari luar Kota Bogor melebihi kuota maksimal 10\%. Hal tersebut diantaranya disebabkan oleh kualitas sekolah yang relatif belum seragam dan kemudahan transportasi menuju sekolah.

Faktor yang secara nyata/ signifikan mempengaruhi pemilihan moda angkutan siswa SDN menuju sekolah adalah jarak sekolah, lama perjalanan, biaya perjalanan, pertimbangan biaya, pertimbangan berjalan kaki, dan pertimbangan waktu, sedangkan untuk siswa SMPN adalah jenis kelamin, jarak sekolah, lama perjalanan, dan biaya perjalanan. Lebih dari separuh (51\%) siswa SDN menggunakan angkot ke tempat sekolah sementara siswa lainnya menggunakan kendaraan umum berbasis online, berjalan kaki, dan menggunakan angkutan antar jemput berturut-turut sebesar 20\%, 19\% dan 10\%. Sebagian besar (73\%) siswa SMPN yang menggunakan angkot, kendaraan umum berbasis online $17 \%$, berjalan kaki 6\%, dan menggunakan angkutan antar jemput sebesar $4 \%$.

Arahan pengembangan transportasi sekolah difokuskan pada penerapan ketentuan zonasi yang dijalankan secara maksimal agar pergerakan siswa menuju sekolah lebih teratur sesuai dengan zonanya serta pengelolaan bus sekolah yang disesuaikan dengan cluster sekolah.

\section{DAFTAR PUSTAKA}

Abas AY, Jensen F, Timboeleng JA. 2012. Analisis Garis Keinginan Pergerakan Masyarakat Pengguna Transportasi di Kabupaten Bolaang Mongondow Timur Provinsi Sulawesi Utara. Jurnal Ilmiah MEDIA ENGINEERING, 2 (2): 126-134.

Badan Standarisasi Nasional. 2004. SNI 03-1733-2004 tentang Tata Cara Perencanaan Lingkungan Perumahan di Perkotaan. Jakarta (ID): Badan Standarisasi Nasional. 
Batti, JF. 2011. Studi Karakteristik Pelaku Perjalanan dalam Wilayah Pelayanan Trayek Mamboro-Manonda di Kota Palu. Jurnal Rekayasa dan Manajemen Transportasi, 1 (2): 119-128.

Brotodewo, N. 2010. Penilaian Indikator Transportasi Berkelanjutan pada Kawasan Metropolitan di Indonesia. Jurnal Perencanaan Wilayah dan Kota, 21 (3): 165 - 182.

Djakfar L, Indriastuti AK, Nasution AS. 2010. Studi Karakteristik dan Model Pemilihan Moda Angkutan Mahasiswa Menuju Kampus (Sepeda Motor atau Angkutan Umum) di Kota Malang. Jurnal Rekayasa Sipil, 4 (1): 37-51.

Hosmer DW, Hosmer T, Cessie SL, Lemeshow S. 1997. A Comparison Of Goodness-Of-Fit Tests For The Logistic Regression Model. Statistics In Medicine, 16: 965-980.

Hosmer DW, Lemeshow S. 2000. Applied Logistic Regression, $2^{\text {nd }}$ edition. New York (US): John Wiley and Sons.

Kementerian Pendidikan dan Kebudayaan. 2018. Peraturan Menteri Pendidikan Dan Kebudayaan Nomor 14 Tahun 2018. Jakarta (ID): Kementerian Pendidikan dan Kebudayaan.

Kementerian Perhubungan. 2016b. Perhubungan Darat Dalam Angka Tahun 2015. Jakarta (ID): Kementerian Perhubungan.

Liu, Ying. 2007. On Goodness-of-Fit of Logistic Regression Model. [Disertasi] Kansas (US). Kansas State University.

Maharani II, Hardinsyah, Sumantri B. 2007. Aplikasi Regresi Logistik dalam Analisis Faktor Risiko Anemia Gizi pada Mahasiswa Baru IPB. Jurnal Gizi dan Pangan, 2(2):36-43.

Mansyur U, Sitorus SRP, Marimin, Prasetyo LB, Poerwo IFP. 2009. Model Pengelolaan Transportasi Angkutan Umum Penumpang Nonbus Berkelanjutan Kota Makassar. Forum Pascasarjana, 32 (4): 227237.

Rau S, Liputo A. 2008. Analisa Permodelan Bangkitan Pergerakan Lalu Lintas pada Tata Guna Lahan SMU Negeri di Makassar. Prosiding. Simposium XI FSTPT, 29-30 Oktober 2008, hal. 1-10.

Sugianto G, Malkhamah S. 2009. Model Pemilihan Moda Antara Mobil Pribadi dan Bus Transjogja Akibat Penerapan Biaya Kemacetan. Jurnal Transportasi, 9(2): 97-106.

Tamin OZ, Frazila RB. 1997. Penerapan Konsep Interaksi Tata Guna Lahan-Sistem Transportasi dalam Perencanaan Sistem Jaringan Transportasi. Jurnal Perencanaan Wilayah dan Kota, 8 (3): 34-52. 